\title{
Inhibition of Axonal Growth by Brefeldin A in Hippocampal Neurons in Culture
}

\author{
Mark Jareb and Gary Banker \\ Department of Neuroscience, University of Virginia School of Medicine, Charlottesville, Virginia 22908
}

The outgrowth of neuronal processes involves a great increase in the surface area of the cell. The supply of membrane material necessarily must be coordinated with the demands for neurite growth. The selective growth of only one or two neurites at any given time during the development of polarity raises the possibility that the production of materials by the soma is limiting for growth (Dotti and Banker, 1987; Dotti et al., 1988; Goslin and Banker, 1990). To examine the role of the availability of membrane components during the development of polarity and axonal elongation, we treated neurons with brefeldin $A$, an antibiotic that disrupts the trafficking of vesicles from the Golgi complex to the plasma membrane. Treatment with brefeldin A
(1 $\mu \mathrm{g} / \mathrm{ml}$ ) inhibited axonal growth within $0.5 \mathrm{hr}$; in unpolarized cells it prevented the formation of an axon. These results indicate that the availability of membrane components of Golgiderived vesicles is required for axonal growth and hence the development of polarity. Inhibitors of protein and RNA synthesis also blocked axonal growth and the development of polarity, but over a much slower time course. This suggests that the full complement of proteins and mRNAs required for the initial development of polarity is present for several hours before polarity is actually established.

Key words: polarity; neurite outgrowth; hippocampal neurons; brefeldin A; Golgi complex; axonal transport
Axonal growth involves a great increase in volume and surface area. Hence, growth cone advance and the transport of cytoskeletal and membrane constituents must be linked. The selective transport of these constituents may underlie the selective outgrowth of neurites observed during synapse formation or the development of neuronal polarity (Dotti et al., 1988; O'Rourke and Fraser, 1990). Indeed, differential transport of vesicular elements has been observed directly in different branches of the neurites of cultured Aplysia neurons (Goldberg and Schacher, 1987).

Few experiments have examined the link between axonal growth and the supply of materials produced in the cell body. One such experiment used optical tweezers to trap materials transported along the neurites of chick sensory neurons (Martenson et al., 1993). This led, after a delay of minutes, to collapse of the growth cone and cessation of elongation. The latency between blockade of vesicle transport and inhibition of growth suggested that outgrowth depends, on a moment-to-moment basis, on the delivery of some element moving by rapid axonal transport.

Disruption of axonal transport may simultaneously interrupt the supply of membrane constituents, cytoskeletal elements, and regulatory components governing their assembly. To investigate more specifically the importance of membrane elements in neu-

\footnotetext{
Received July 2, 1997; revised Aug. 29, 1997; accepted Sept. 16, 1997.

This research was supported by the National Institutes of Health Grant NS 17112; M.J. was supported in part by the National Institutes of Health Training Grant HD07323. We thank Hannelore Asmussen for preparation of neuronal cultures, Jason Cooper and Gordon Ruthel for help with time-lapse video microscopy, Michelle Burack and Elaine Lowe for help with this manuscript, and Dr. Robert Gerard for the generous gift of adenoviruses.

Correspondence should be addressed to Dr. Gary Banker, Center for Research on Occupational and Environmental Toxicology, Oregon Health Sciences University, 3181 Southwest Sam Jackson Park Road, Portland, OR 97201-3098.

Dr. Jareb's present address: Center for Neurobiology and Behavior, Columbia University, 722 West 168th Street, PI Annex Room 807, New York, NY 10032.

Copyright (C) 1997 Society for Neuroscience $0270-6474 / 97 / 178955-09 \$ 05.00 / 0$
}

rite growth, we have examined the effects of brefeldin A (BFA) on the development of cultured hippocampal neurons. BFA acts by inhibiting a Golgi-associated guanine nucleotide exchange protein acting on ADP-ribosylation factor (ARF) (Donaldson et al., 1992; Helms and Rothman, 1992). Because ARF1 plays a central role in controlling vesicular traffic from the endoplasmic reticulum (ER) to the Golgi complex and between successive Golgi compartments, BFA treatment results in the redistribution of coat proteins from Golgi membranes to cytosol, the inhibition of vesicular traffic from the Golgi complex, and the collapse of the Golgi complex into the ER (Dascher and Balch, 1994; Elazar et al., 1994; Zhang et al., 1994). BFA also affects the recycling of endocytosed proteins also via ARF family members, but unlike the biosynthetic pathway, membrane recycling continues, although at a slower rate (Damke et al., 1991; Lippincott-Schwartz et al., 1991; Barroso and Sztul, 1994; Schonhorn and WesslingResnick, 1994; Stoorvogel et al., 1996). In cultured hippocampal neurons, the cell surface expression of proteins via defective herpesvirus vectors and the appearance of Golgi-derived vesicles labeled with fluorescent lipids are blocked by BFA treatment (Craig et al., 1995).

In this report we examine the effects of BFA on neurite outgrowth and the development of polarity. We confirm that BFA rapidly and reversibly disrupts the Golgi complex and prevents the cell surface expression of exogenous membrane proteins in cultured hippocampal neurons. We then show that neurons that have not yet formed axons fail to do so in the presence of BFA. In neurons that have formed axons at the time of exposure to BFA, axonal elongation ceased within $30 \mathrm{~min}$. Inhibitors of protein synthesis also block the formation and elongation of axons, but their effects on neurite growth are apparent only after several hours.

\section{MATERIALS AND METHODS}

Materials. Brefeldin A (Epicentre Technologies, Madison, WI) was stored at $-20^{\circ} \mathrm{C}$ as a stock solution of $5 \mathrm{mg} / \mathrm{ml}$ in ethanol. BFA was added 
directly to the culture medium at a final concentration of $3.57 \mu \mathrm{M}(1$ $\mu \mathrm{g} / \mathrm{ml}$ ) in all experiments, unless otherwise noted. Cycloheximide (71 $\mu \mathrm{M} ; 7.1 \mathrm{~mm}$ aqueous stock solution), emetine (40 $\mu \mathrm{M} ; 1.6 \mathrm{~mm}$ aqueous stock solution), or puromycin (50 $\mu \mathrm{M} ; 2 \mathrm{~mm}$ aqueous stock solution) was added to the medium to inhibit protein synthesis. Actinomycin D $(8 \mu \mathrm{M}$; $1.6 \mathrm{~mm}$ aqueous stock solution) was added to the medium to inhibit the synthesis of RNA. The cultures were rinsed twice in MEM, and then glial-conditioned medium was added to the dish to examine the effects of drug removal.

Cell culture. Methods for preparing hippocampal cell cultures have been described previously (Goslin and Banker, 1992). In brief, cell suspensions were prepared by trypsin treatment of hippocampi (dissected from the brains of $18 \mathrm{~d}$ rat fetuses) and trituration using a fire-polished Pasteur pipette. Dissociated cells were plated on poly-L-lysine-treated glass coverslips in MEM. After allowing 3-4 hr for cells to adhere, we transferred the coverslips to a new dish, such that a space of $\sim 1 \mathrm{~mm}$ separated the coverslip from a monolayer of glia. The medium in this dish was glial-conditioned MEM containing the N2 supplements of Bottenstein and Sato (1979), together with sodium pyruvate and ovalbu$\min (0.1 \%)$

For experiments involving video microscopy of individual neurons, coverslips were placed in sealed chambers designed for time-lapse microscopy or in special culture dishes prepared as described by Goslin and Banker (1990).

Visualization of the Golgi apparatus. One-day-old neurons were fixed in cold $\mathrm{MeOH}$, and the Golgi complex was visualized with an antibody to the Golgi protein mannosidase II (generous gift of Dr. Kelly Moremen, University of Georgia, Athens, GA, and Dr. Marilyn Farquahr, University of California, San Diego, San Diego, CA). The rabbit polyclonal antibody was incubated at a dilution of $1: 1000$, followed by incubations in biotinylated goat anti-rabbit IgG (1:800; Vector Laboratories, Burlingame, CA) and then in FITC-streptavidin (1:800; Vector).

The Golgi complex was also visualized by staining living cells with $N$-(4,4-difluoro-5,7-dimethyl-bora-3a,4a-diaza-s-indacene-3-pentanoyl) sphingosine (DMB-ceramide). A complex of DMB-ceramide with defatted BSA was prepared by adding $100 \mu \mathrm{l}$ of a $500 \mu \mathrm{M}$ stock of DMBceramide to $10 \mathrm{ml}$ of MEM containing defatted BSA $(0.34 \mathrm{mg} / \mathrm{ml})$, as described by Lipsky and Pagano (1985). This solution was then dialyzed against $500 \mathrm{ml}$ of MEM overnight at $4^{\circ} \mathrm{C}$, resulting in a final concentration of $\sim 5 \mu \mathrm{M}$ for both DMB-ceramide and the defatted BSA. Cultures were incubated with the $5 \mu \mathrm{M}$ DMB-ceramide and defatted BSA complex in MEM for $15 \mathrm{~min}$ at $37^{\circ} \mathrm{C}$. After incubation, the MEM was replaced with glial-conditioned medium, and cells were examined by fluorescence microscopy using a planapo $63 \times$ objective.

Expression of exogenous proteins. To test the actions of BFA on the transport of integral membrane proteins to the cell surface in cultured neurons, we expressed exogenous proteins using replication-defective adenovirus. Adenovirus expressing low density lipoprotein receptor (LDLR) (generous gift of Dr. Robert Gerard, University of Texas, Southwestern Medical Center, Dallas, TX; Herz and Gerard, 1993) was added to cultures $18 \mathrm{hr}$ after plating, and BFA was added $4 \mathrm{hr}$ later. Cell surface expression from adenovirus vectors is first detectable $8 \mathrm{hr}$ after infection (M. Jareb and G. Banker, unpublished observations). LDLR expression in control and BFA-treated cultures was visualized with the monoclonal antibody C7 (Amersham, Arlington Heights, IL) $12 \mathrm{hr}$ after BFA treatment (16 hr after infection). To examine cell surface staining, we incubated living neurons with primary antibody for $5 \mathrm{~min}$ at $37^{\circ} \mathrm{C}$ and then fixed the neurons in $4 \%$ paraformaldehyde and $4 \%$ sucrose in PBS. Other cultures were fixed and permeabilized before staining to reveal both intracellular and surface labeling.

Effects of inhibitors on development of polarity. The effect of inhibitors on the morphological development of cultured hippocampal neurons was examined by treating cultures with a drug during the period when most neurons initially form their axons. Cultures were treated with BFA, cycloheximide (CHX), actinomycin D (ACT D), or vehicle $18 \mathrm{hr}$ after plating and then fixed in $2.5 \%$ glutaraldehyde $1-12 \mathrm{hr}$ later. Randomly chosen fields were examined, and the proportion of cells that had developed axons was determined. A cell was considered to have an axon if the length of one process was at least twice as long as any other process and was more than twice the diameter of the cell body (Deitch and Banker, 1993). Cells with multiple axons were not counted. At least 100 cells from each of two or three coverslips were examined. Repeated-measures ANOVA was used to compare mean changes in the percentage of neurons with axons after drug treatment. When appropriate, post hoc
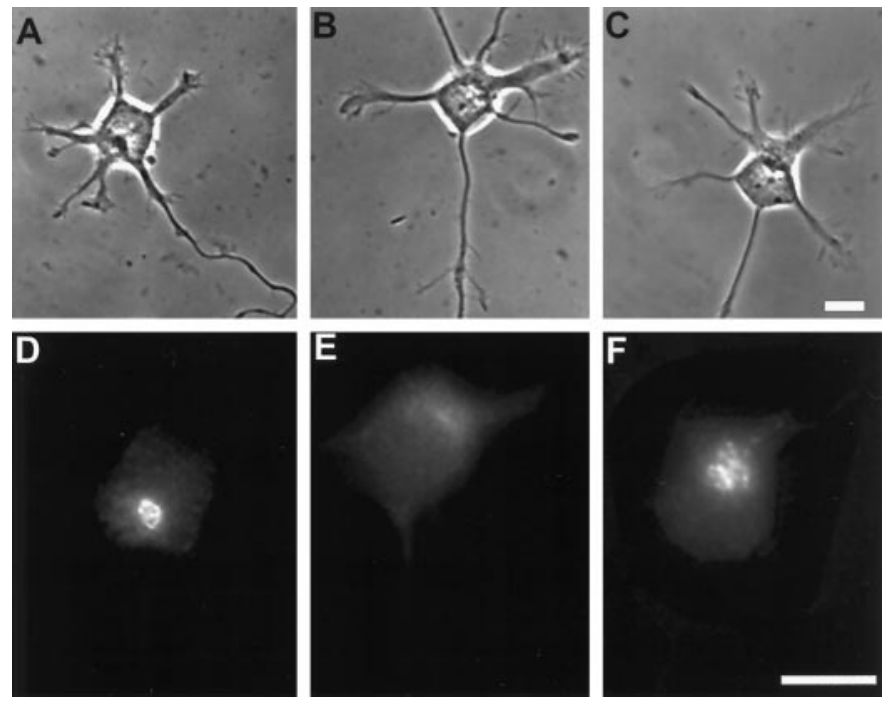

Figure 1. The effects of brefeldin A on the organization of the Golgi complex in cultured hippocampal neurons. The Golgi complex was visualized with a polyclonal antibody against the Golgi resident protein mannosidase II. Fluorescent micrographs were enlarged to show somata $(D-F)$. In control neurons $(A, D)$, the nucleus typically lies at one pole of the cell, and the Golgi complex is present as a single discrete spot near the edge of the nucleus that faces the cytoplasm. After exposure to BFA (3.57 $\mu \mathrm{M})$ for $15 \mathrm{~min}(B, E)$, mannosidase II immunoreactivity was diffusely distributed throughout the cytoplasm. Within $30 \mathrm{~min}$ after removal of BFA $(C, F)$, the Golgi complex had nearly regained its normal position and appearance. Scale bars, $10 \mu \mathrm{m}$.

comparisons between control and drug-treated cultures were made using Student's $t$ tests.

Effects of inhibitors on neurite elongation. The effect of inhibitors on neurite elongation was examined by following the growth of individual cells, beginning $\sim 24 \mathrm{hr}$ after plating. Cells at stage 3 of development were chosen, and their positions were marked on the coverslip with a diamond-tipped object marker. Observations were made at intervals of $0.5-3 \mathrm{hr}$, beginning $2 \mathrm{hr}$ before drug addition and continuing for up to 12 hr. Between observations, the cultures were returned to the incubator. During each experiment, 12 randomly chosen stage 3 cells were followed from both drug-treated and vehicle-treated cultures. Process length was measured using Image-1 image analysis software (Universal Imaging Corporation, West Chester, PA). Repeated-measures ANOVA was used to compare mean changes in the relative length of axons or minor processes after drug treatment. When appropriate, post hoc comparisons between control and drug-treated cultures were made using Student's $t$ tests.

\section{RESULTS}

\section{Brefeldin A disrupts the Golgi complex in hippocampal neurons and prevents the cell surface expression of membrane proteins}

We examined the effects of BFA on the organization of the Golgi complex in cultured hippocampal neurons, visualizing the Golgi complex with a rabbit polyclonal antibody to the Golgi resident protein mannosidase II. In all control neurons (Fig. 1), the Golgi complex formed a discrete spot, which was usually associated with an indentation in the nucleus that faces the cytoplasm of the soma, as described previously (Dotti and Banker, 1991; Deitch and Banker, 1993). Treatment with BFA (3.57 $\mu \mathrm{M})$ rapidly and reversibly disrupted the Golgi complex. Within $15 \mathrm{~min}$, in every BFA-treated neuron, the Golgi complex became dispersed throughout the cytoplasm of the cell body (Fig. 1). Thirty minutes after BFA was removed, the Golgi complex in most neurons had assumed its normal appearance and localization (Fig. 1). Similar 

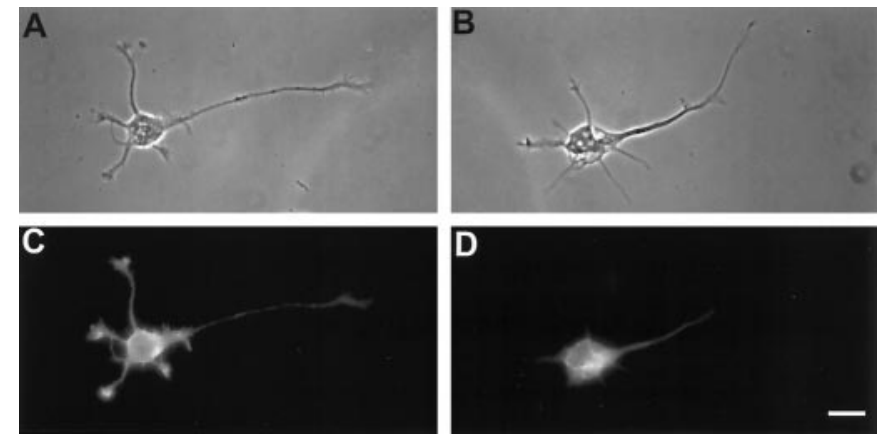

Figure 2. The effects of brefeldin A on the cell surface expression of proteins in cultured hippocampal neurons by replication-defective adenovirus. LDLR was expressed in 1-d-old neurons using replication-defective adenovirus. The distribution of LDLR was visualized by immunofluorescence. The fluorescence micrographs illustrate a representative cell from a control culture $16 \mathrm{hr}$ after infection $(A, C)$ and from a culture exposed to BFA $(3.57 \mu \mathrm{M}) 4 \mathrm{hr}$ after infection and fixed $12 \mathrm{hr}$ later $(B, D)$. In the control cultures, cell surface labeling was observed on minor processes, the cell body, and the proximal axon. In BFA-treated cultures, labeling was confined primarily to the cell body and exhibited a tubular appearance. When BFA-treated cultures were exposed to antibody before fixation (to prevent intracellular labeling), no staining was observed. Scale bar, $20 \mu \mathrm{m}$.

results were obtained when DMB-ceramide, a fluorescent lipid analog, was used to visualize the Golgi complex in living cells (data not shown) (Pagano et al., 1991).

We tested the ability of BFA treatment to block protein transport through the Golgi complex in rat hippocampal neurons by expressing an exogenous membrane protein, the LDLR, using an adenovirus vector. BFA was added to cultures $4 \mathrm{hr}$ after infection, and LDLR expression was examined $12 \mathrm{hr}$ later. In control neurons LDLR was expressed on the surface of minor processes, cell bodies, and proximal portions of the axon (Fig. 2). Live staining of sister cultures treated with BFA and infected with LDLR adenovirus revealed no detectable surface labeling (data not shown). To confirm that BFA-treated cultures were infected, we detected LDLR expression in permeabilized neurons, in which it exhibited a tubular appearance consistent with an intracellular localization (Fig. 2). This is consistent with previous work that shows that cell surface expression of the T-cell marker CD8 introduced into rat hippocampal neurons via replication-defective herpesviruses is blocked by BFA (Craig et al., 1995).

\section{Brefeldin A inhibits the development of polarity}

During the first $48 \mathrm{hr}$ after plating, the vast majority of hippocampal neurons undergo the transformation from a round, unpolarized cell to a polarized neuron with a single axon. Most cells develop axons and acquire a polarity between 18 and $36 \mathrm{hr}$ after plating. To determine whether exposure to BFA influences the development of polarity, we examined the effects of adding BFA $(3.57 \mu \mathrm{M})$ to hippocampal cultures $18 \mathrm{hr}$ after plating. Figure 3 illustrates representative fields from a control culture $24 \mathrm{hr}$ after plating and from a culture treated with BFA $18 \mathrm{hr}$ after plating and examined $6 \mathrm{hr}$ later. In the untreated culture (Fig. 3A), approximately half of the neurons have formed a single axon in addition to several minor processes (stage 3 of Dotti et al., 1988). The other neurons had several minor processes but had not yet developed axons (stage 2 of development). In the culture treated with BFA (Fig. 3B), most of the neurons had not formed axons.

We quantified the effects of BFA on the development of morphological polarity by fixing cultures at varying times after the
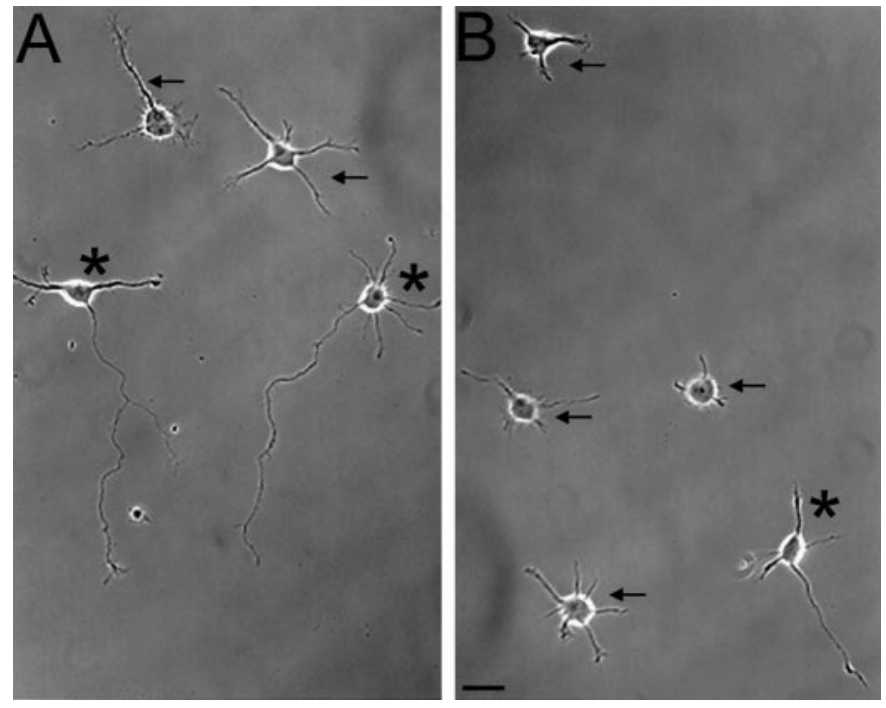

Figure 3. The effects of brefeldin A on the morphological development of cultured hippocampal neurons. The phase contrast micrographs illustrate representative fields from a control culture $24 \mathrm{hr}$ after plating $(A)$ and from a culture exposed to BFA $(3.57 \mu \mathrm{M}) 18 \mathrm{hr}$ after plating and photographed $6 \mathrm{hr}$ later $(B)$. In the control culture, half of the neurons have become polarized (asterisks), i.e., they had formed a single, long axon as well as several, short, minor processes. The other neurons had minor processes but had not yet developed axons (arrows). In cultures treated with BFA, unpolarized cells predominate. Scale bar, $20 \mu \mathrm{m}$.

addition of BFA and counting the number of neurons that had formed axons (Fig. 4). In control cultures, the percentage of neurons with axons increased at an approximately linear rate ( $\sim 3 \%$ of cells formed axons each hour), with $\sim 50 \%$ of the cells having formed axons by $30 \mathrm{hr}$ after plating. In cultures treated with BFA, the normal increase in the percentage of neurons with axons was significantly reduced within $1 \mathrm{hr}(p<0.05)$. Six hours after adding BFA, the percentage of neurons with axons had actually fallen slightly. After removal of BFA, cells resumed forming axons at the rate observed in control cultures. As shown in Figure $4 B$, inhibition of the development of polarity by BFA was dose-dependent. Axonal development was significantly inhibited at $0.71 \mu \mathrm{M}$ BFA and was completely blocked at a concentration of $3.57 \mu \mathrm{M}$. No significant inhibition of axonal development was observed at a concentration of $0.14 \mu \mathrm{M}$ BFA.

Although it is not surprising that a drug that blocks secretion and disrupts pathways through the Golgi complex might interfere with the formation of the axon, we were struck by the rapidity of its action on axonal development. To provide a frame of reference for this result, we compared the time course of action of BFA with that of cycloheximide, an inhibitor of protein synthesis, and actinomycin D, an RNA synthesis inhibitor. Obviously, blockade of protein synthesis generally (either directly or by depletion of mRNAs) or of the Golgi-mediated synthesis of membrane constituents is ultimately likely to block neurite outgrowth and therefore the development of neuronal polarity. Hence, these experiments were intended to compare the time courses of the effects of these drugs on the development of polarity.

Figure 5 compares the effects of BFA $(3.57 \mu \mathrm{M})$, cycloheximide $(\mathrm{CHX} ; 71 \mu \mathrm{M})$, and actinomycin D (ACT D; $8 \mu \mathrm{M})$. BFA inhibited the development of polarity much more rapidly than either CHX or ACT D. Compared with control cultures, the change in the percentage of BFA-treated neurons with axons was significantly reduced within $1 \mathrm{hr}$ after drug addition $(p<0.05)$. In 

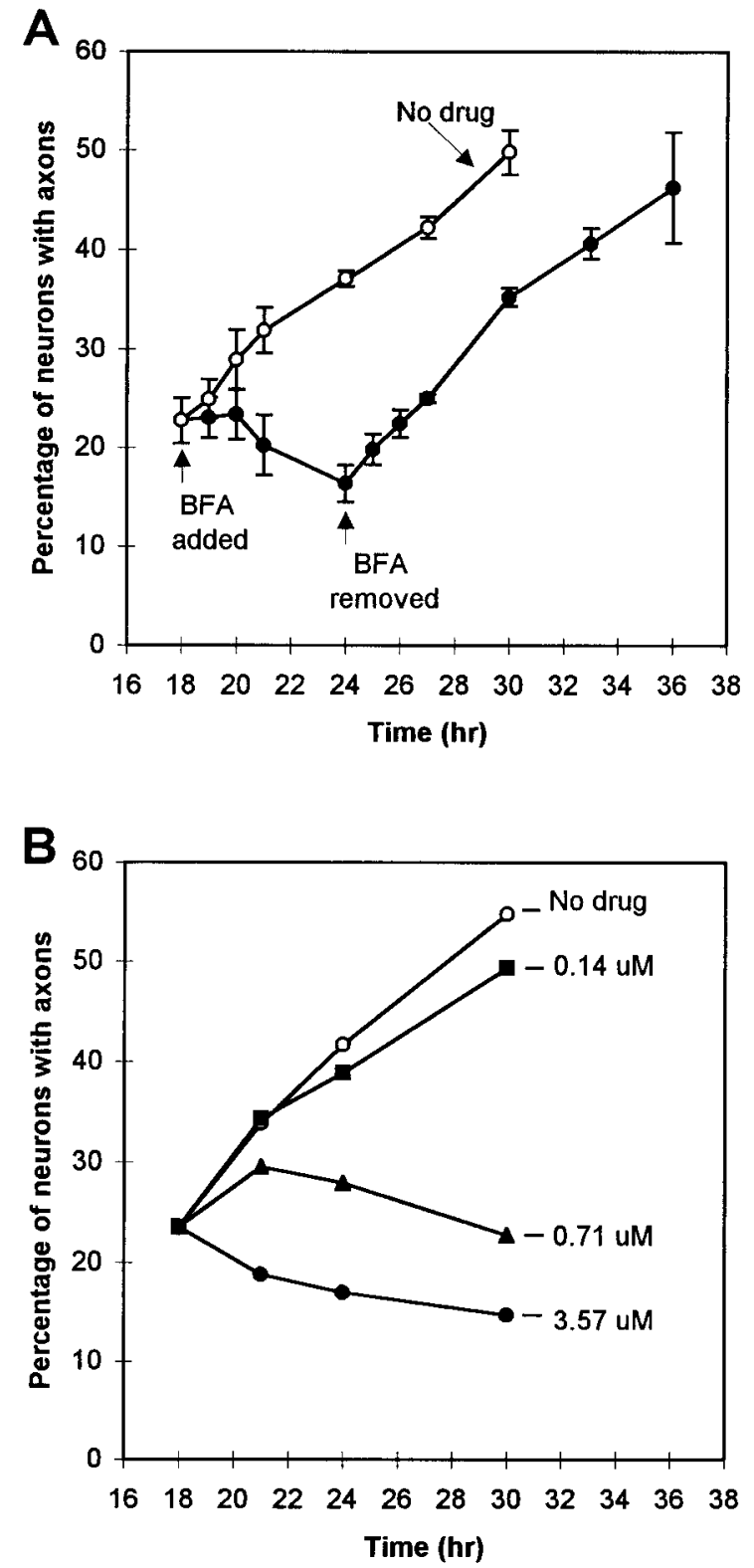

Figure 4. Brefeldin A inhibits the development of morphological polarity by cultured hippocampal neurons. $A$, Cultures were treated with BFA $(3.57 \mu \mathrm{M})$ at $18 \mathrm{hr}$ after plating and examined at varying times later. In control cultures (open circles), $\sim 23 \%$ of the cells had become polarized 18 $\mathrm{hr}$ after plating, and the proportion of cells that developed axons increased at an approximately linear rate during the next $12 \mathrm{hr}$. In the presence of BFA (filled circles), there was no increase in the number of cells that developed axons. By $3 \mathrm{hr}$ there was a slight but significant decrease in the proportion of polarized cells. If BFA was removed after 6 $\mathrm{hr}$ of exposure, cells resumed axonal development at approximately the same rate observed in control cultures. Time points for BFA-treated and control cultures represent means from four experiments. Time points from cultures in which BFA was removed represent means from two experiments. In each experiment at each time point, two or three coverslips were fixed, and the proportion of cells with axons was determined, based on counts of 200-300 cells. $B$, The effects of brefeldin A on axonal development were dose-dependent. Cultures were treated with BFA at concentrations of $0.14 \mu \mathrm{M}$ (filled squares), $0.71 \mu \mathrm{M}$ (filled triangles), or $3.57 \mu \mathrm{M}$ (filled circles). At the highest concentration tested (3.57 $\mu \mathrm{M})$, axonal development was completely inhibited. Lower concentrations (as low as $0.71 \mu \mathrm{M}$ ) significantly reduced the rate of axonal development. Time points represent means from two experiments. In each experiment at each time point, two or three coverslips were fixed, and the proportion of cells with axons was determined, based on counts of 200-300 cells.

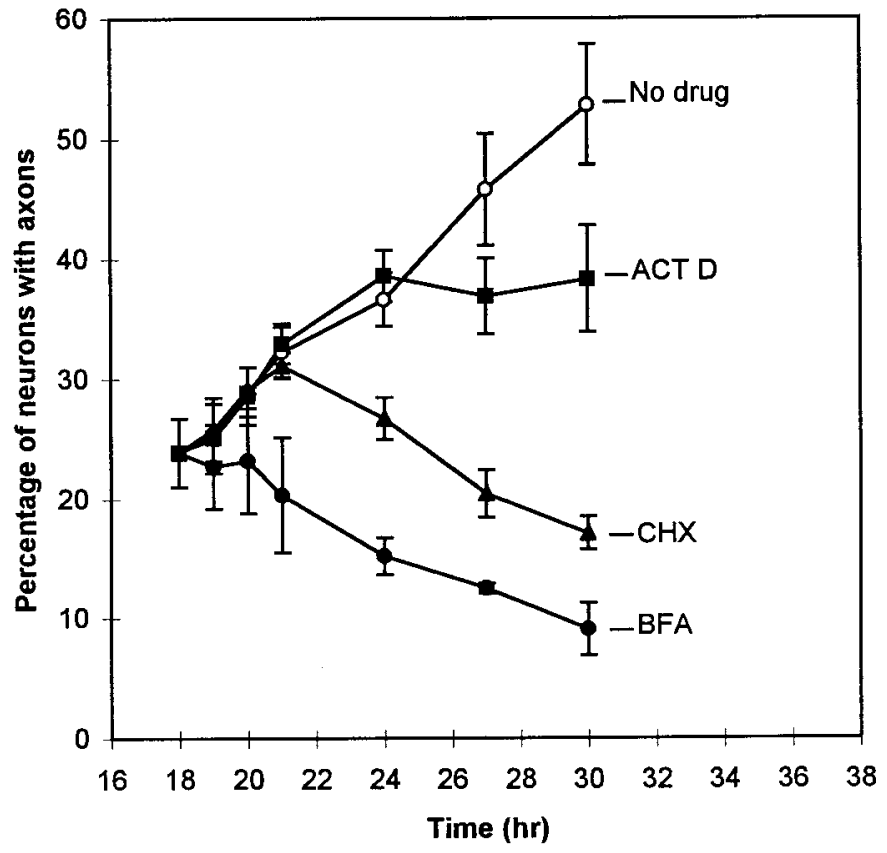

Figure 5. Brefeldin A inhibits the development of polarity more rapidly than do inhibitors of protein or RNA synthesis. Cultures were treated with BFA (3.57 $\mu \mathrm{M}$; filled circles), cycloheximide (71 $\mu \mathrm{M}$; filled triangles), or actinomycin $\mathrm{D}(8 \mu \mathrm{M}$; filled squares $)$ at $18 \mathrm{hr}$ after plating and examined at varying times later. In control cultures (open circles), the proportion of neurons that developed axons increased at an approximately constant rate. All three drugs inhibited the development of a polarized morphology, but the effects of BFA were much more rapid. After addition of BFA, a reduction in the expected increase in the number of polarized cells was evident by $1 \mathrm{hr}$ ( $p<0.05$, compared with control cultures). A statistically significant reduction in the proportion of neurons that had developed axons was first apparent $6 \mathrm{hr}$ after addition of cycloheximide and $9 \mathrm{hr}$ after addition of actinomycin D. Time points represent means from three experiments. In each experiment at each time point, two or three coverslips were fixed, and the proportion of cells with axons was determined, based on counts of 200-300 cells.

contrast, the change in the percentage of polarized neurons in cultures treated with $\mathrm{CHX}(71 \mu \mathrm{M})$ was significantly reduced in comparison with controls only after $6 \mathrm{hr}$ of treatment $(p<0.05)$. This concentration of CHX inhibits protein synthesis in cultured hippocampal neurons by $>90 \%$ (Kleiman et al., 1993). Similar results were observed with emetine $(18 \mu \mathrm{M})$ and puromycin (46 $\mu \mathrm{M}$ ), protein synthesis inhibitors with different modes of action than CHX. Inhibition of the development of polarity by ACT D $(8 \mu \mathrm{M})$ followed an even longer time course. These data show that BFA has a much more rapid effect on the development of polarity than does the inhibition of either RNA or protein synthesis.

\section{The effects of BFA on axonal elongation}

To determine whether BFA also inhibits the elongation of axons that have formed previously, we followed the growth of individual cells in BFA by video microscopy for up to $12 \mathrm{hr}$. Figure 6 illustrates a typical example. Before the addition of BFA, the axon of this cell was elongating at $5 \mu \mathrm{m} / \mathrm{hr}$. Within $1 \mathrm{hr}$ of treatment, axonal elongation had ceased completely. After $3 \mathrm{hr}$, a slight retraction of the axon had occurred, and this became more pronounced over time. Although elongation ceased, the morphology and motility of the axonal growth cone appeared normal for $6 \mathrm{hr}$ or more. By comparison with the axon, minor processes were relatively unaffected. Some retraction was observed at 3 and $6 \mathrm{hr}$, 

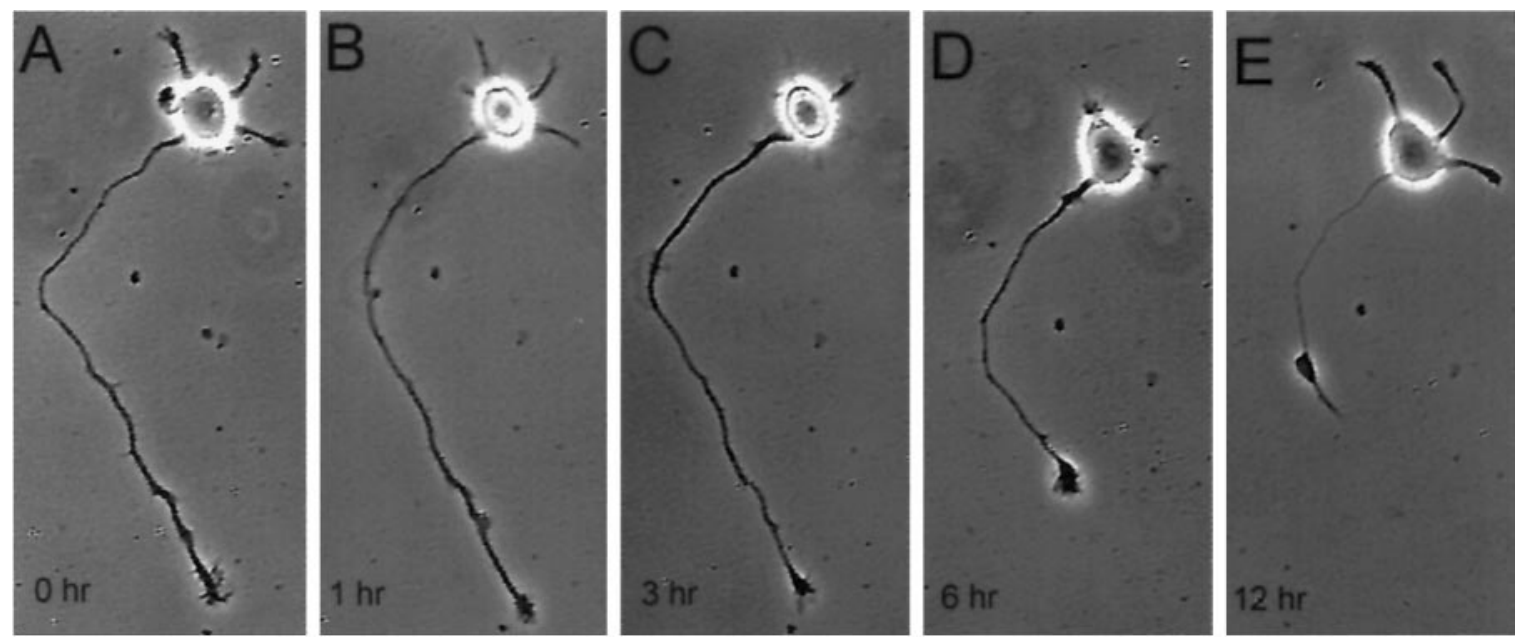

Figure 6. The effects of brefeldin A on neurite elongation. The culture was treated with BFA $(3.57 \mu \mathrm{M}) \sim 24 \mathrm{hr}$ after plating. This series of phase contrast micrographs illustrates a cell just before BFA treatment $(A)$ and $1 \mathrm{hr}(B), 3 \mathrm{hr}(C), 6 \mathrm{hr}(D)$, and $12 \mathrm{hr}(E)$ after addition of BFA. Axonal elongation, which was evident before the addition of BFA, was completely inhibited within the first hour after treatment. After $3 \mathrm{hr}$, retraction of the axon was evident, although the axonal growth cone retained its normal appearance for $>6 \mathrm{hr}$ after addition of BFA. By $12 \mathrm{hr}$, the axon had retracted $>60 \mu \mathrm{m}$, and the axonal growth cone had lost any lamellipodia or filopodia. The minor processes seemed primarily unaffected by treatment with BFA. Scale bar, $20 \mu \mathrm{m}$.

but by $12 \mathrm{hr}$ these processes had re-extended to their former length despite the continued presence of the drug.

To assess further the effects of BFA on growth cone morphology, we followed individual cells by time-lapse recording for up to $12 \mathrm{hr}$ (Fig. 7). After $>6 \mathrm{hr}$ of BFA treatment, $86 \%$ of the neurons still exhibited prominent growth cones. Surprisingly, although BFA-treated neurons showed a marked net retraction of the axon over time, axons still exhibited occasional spurts of growth, and their growth cones remained motile.

The effects of $\mathrm{CHX}$ on axonal elongation were quite different (Fig. 8). In the example shown, the axon continued to elongate at its previous rate for $>3 \mathrm{hr}$ after addition of CHX. Subsequently, elongation stopped, and the axon retracted somewhat, but this was not nearly as pronounced as was observed in BFA-treated neurons. Coincident with inhibition of axonal growth, the axon became noticeably thinner, and its growth cone disappeared. Minor processes of $\mathrm{CHX}$-treated neurons appeared unaffected.

Figure 9 summarizes our observations of the effects of BFA and cycloheximide on the rate of axonal elongation. When BFA was added $\sim 24 \mathrm{hr}$ after plating, the average net growth of axons was significantly reduced within 30 min compared with controls. By 1 $\mathrm{hr}$, axonal elongation was completely inhibited. Net retraction of axons became pronounced by $4 \mathrm{hr}$ after addition of BFA, and by $12 \mathrm{hr}$ axons had retracted an average of $50 \mu \mathrm{m}$. In contrast, the average net growth of CHX-treated axons was significantly inhibited only after $6 \mathrm{hr}$, and the average retraction of axons was much less pronounced than that seen in BFA-treated cultures. Neither drug systematically affected the growth or retraction of minor processes. Minor processes in control cultures exhibited spurts of elongation and retraction of up to $20 \mu \mathrm{m}$, but the average net growth of minor processes over the $12 \mathrm{hr}$ examined was $<1 \mu \mathrm{m}$. Minor processes in drug-treated cultures exhibited similar, dynamic elongation and retraction; neither BFA nor $\mathrm{CHX}$ caused a marked retraction of minor processes.

\section{The effects of BFA on neuronal polarity}

Previous work has shown that transection of the axon in stage 3 cells can alter the polarity of the neuron (Goslin and Banker,
1990). If the axon is transected near the cell body, at approximately the same length as the other processes of the cell, a new axon may form from one of the other minor processes of the cell. In contrast, if the axon is transected at some distance from the cell body, so that the axonal stump remains significantly longer than the other processes of the cell, the transected axon regenerates, maintaining the initial polarity of the cell. We were interested in determining whether axonal retraction induced by BFA could similarly alter the polarity of neurons. We followed individual cells during exposure to BFA to determine the degree of axonal retraction; then we removed BFA and examined the subsequent response of the cell for up to $48 \mathrm{hr}$. Figure 10 illustrates a neuron whose axon retracted back to the length of a minor process after $6 \mathrm{hr}$ of exposure to BFA. When BFA was removed and the cell was examined $12 \mathrm{hr}$ later, it had again formed an axon. The new axon arose not from the original axon but from one of the minor processes. In 4 of 22 cells, the axon retracted so markedly that the length of the axon was within $15 \mu \mathrm{m}$ of the longest minor process. In three of the four cases, the polarity of the cell was altered after removal of BFA. In contrast, in all 18 cases in which the axon retracted, but still remained at least 15 $\mu \mathrm{m}$ longer than the longest minor process, the axon retained its identity after removal of BFA. These data suggest that neurons respond to the BFA-induced changes in axonal length in much the same way as do cells whose axons have been transected.

\section{DISCUSSION}

The elongation of neurites involves a large expansion in surface area and volume. The supply of membranous and cytoskeletal elements must meet the demands of growth. Furthermore, the neurites of cultured neurons exhibit selective growth, suggesting that the materials required for growth are limited in quantity. We compared the roles that different components synthesized in the cell body play during axonal growth and the development of neuronal polarity. Brefeldin A, which blocks traffic through the Golgi complex, rapidly inhibited the development of polarity and selectively inhibited axonal elongation in polarized neurons. In- 

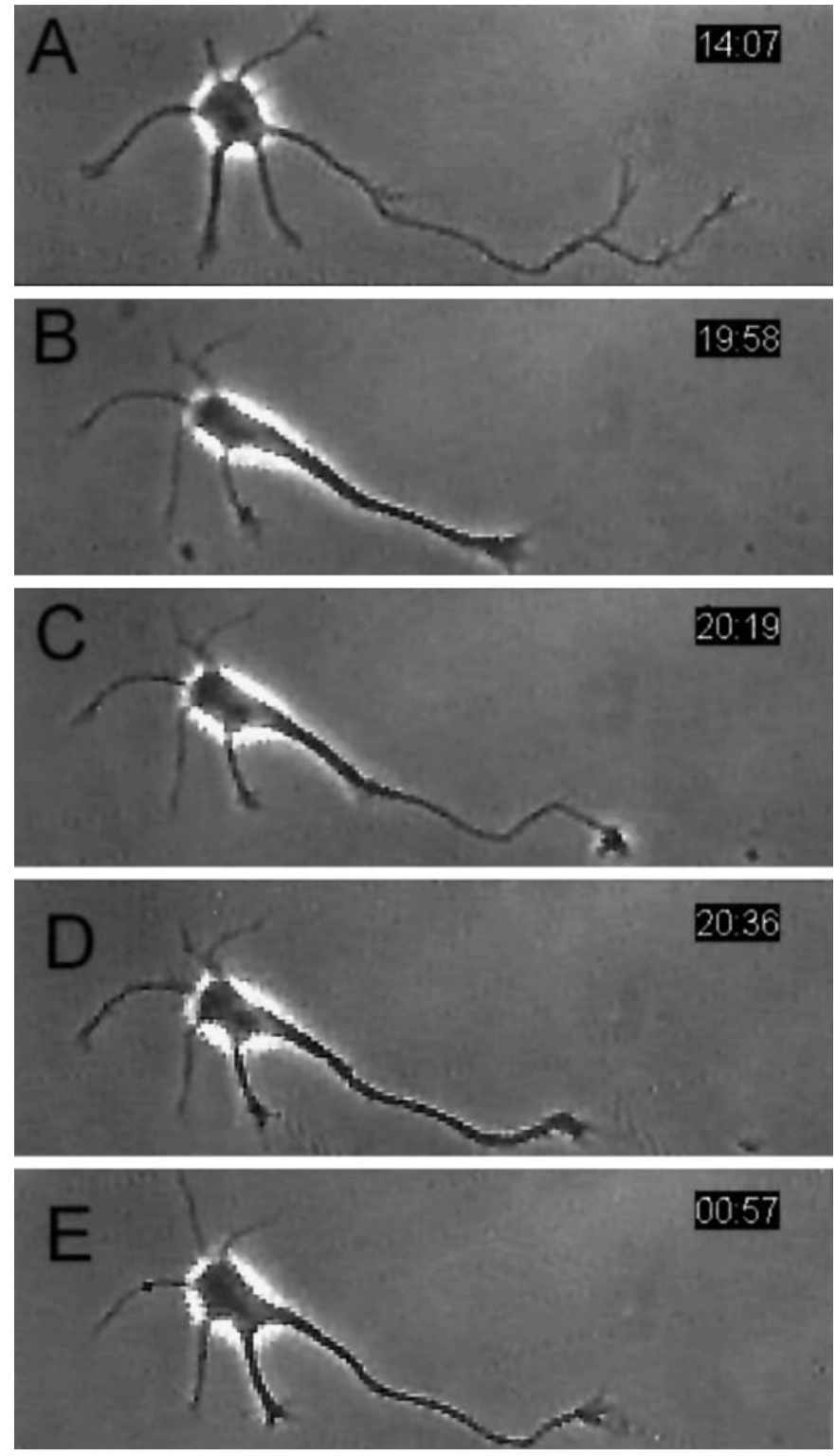

Figure 7. Axonal growth spurts persist for hours in brefeldin A. This set of phase contrast micrographs illustrates a cell just before BFA treatment $(A)$ and at several time points between 6 and $11 \mathrm{hr}$ after the addition of BFA $(B-E)$. At $6 \mathrm{hr}$ after BFA treatment, the axon had retracted markedly $(B)$. Twenty minutes later a growth spurt in excess of $10 \mu \mathrm{m}$ was evident $(C)$. Fifteen minutes later, axonal retraction was observed $(D)$. Several hours later, a motile axonal growth cone still persisted $(E)$. The individual frames shown were taken from a time-lapse video recording in which images were collected every $8 \mathrm{sec}$. Scale bar, $20 \mu \mathrm{m}$.

hibition of protein or RNA synthesis also inhibited axonal outgrowth and the development of polarity, but over a much longer time course. These data suggest that the continuous availability of Golgi-derived components is required for axonal growth.

\section{Mechanism of action of BFA}

The mechanism of action of BFA is critical to the interpretation of the results presented here. BFA acts by inhibiting the GDPGTP exchange on ARF1, a protein necessary for the vesicular traffic from the ER to the Golgi complex and between successive Golgi stacks. One caveat concerning the actions of BFA is that they may differ somewhat among different cell types (Ktistakis et al., 1995, 1996). Rat hippocampal neurons seem to respond to BFA similarly to most other cell types, including other neurons. We showed that the Golgi complex is disrupted by BFA treatment and membrane proteins expressed via adenovirus or herpesvirus are unable to reach the cell surface (Craig et al., 1995). In contrast, Cid-Arregui et al. (1995) found that the cell surface expression of membrane proteins introduced into rat hippocampal neurons with the Semliki Forest virus (SFV) was not blocked by BFA. One possible explanation for this discrepancy is that membrane proteins encoded by SFV may use an ARFindependent mechanism to reach the cell surface. Alternatively, because of rapid expression of proteins via SFV vectors, some surface expression may have occurred before BFA treatment.

In addition to blocking traffic from the Golgi complex in most cells, BFA causes tubulation of the endosomal system and perturbs the recycling of endocytosed proteins (Damke et al., 1991; Schonhorn and Wessling-Resnick, 1994; Stoorvogel et al., 1996). However, unlike the action of BFA on the biosynthetic pathway, membrane traffic through recycling compartments can continue, although at a slower rate (Damke et al., 1991; LippincottSchwartz et al., 1991; Barroso and Sztul, 1994; Schonhorn and Wessling-Resnick, 1994). Because BFA causes tubulation of endosomes in hippocampal neurons (Mundigl et al., 1993), protein recycling likely is also slowed by BFA. Because protein recycling still continues, the effects of BFA caused by perturbation of endocytic processes would be much less severe compared with the complete inhibition of traffic from the Golgi complex.

In Madin-Darby canine kidney cells, a polarized epithelial cell line, BFA also disrupts membrane recycling. A number of apical and basolateral proteins are recycled indiscriminately to both domains in the presence of BFA (Hunziker et al., 1991; Prydz et al., 1992; Wan et al., 1992; Matter et al., 1993). De Hoop et al. (1995) suggested that a similar missorting of endocytosed proteins may occur in hippocampal neurons. Indiscriminate recycling of axonal membrane proteins could play a role in the effects of BFA on axonal elongation, although this would likely be secondary to its blockade of Golgi-derived traffic.

\section{Inhibition of axonal growth during BFA treatment}

The most dramatic effect of BFA treatment was the rapid inhibition of axonal growth. In polarized neurons, within $30 \mathrm{~min}$ of treatment, axonal elongation ceased, and shortly thereafter the axon started to retract. In unpolarized cells, BFA prevented the initiation of axonal outgrowth that marks the initial establishment of polarity. This time course of inhibition is consistent with the fastest rates of vesicle traffic observed from the ER to the cell surface (Wieland et al., 1987; Young et al., 1992; Andreose et al., 1996), suggesting that axonal elongation is blocked concomitantly with the depletion of Golgi-derived vesicles. Studies that blocked organelle transport using optical tweezers further support this idea (Martenson et al., 1993). The time course of inhibition of axonal growth correlated with the estimated time of fast axonal transport from the site of blockade to the growth cone. On the other hand, work showing that axonal membrane flow in chick DRG neurons is considerably greater than their elongation rate suggests a considerable pool of membrane is available for growth (Dai and Sheetz, 1995).

What Golgi-derived materials are crucial for the maintenance and regulation of axonal growth and the development of polarity? One possibility is that the continuous availability of one or more membrane proteins is required to sustain axonal growth. The differences between the inhibitory effects of BFA and CHX argue 

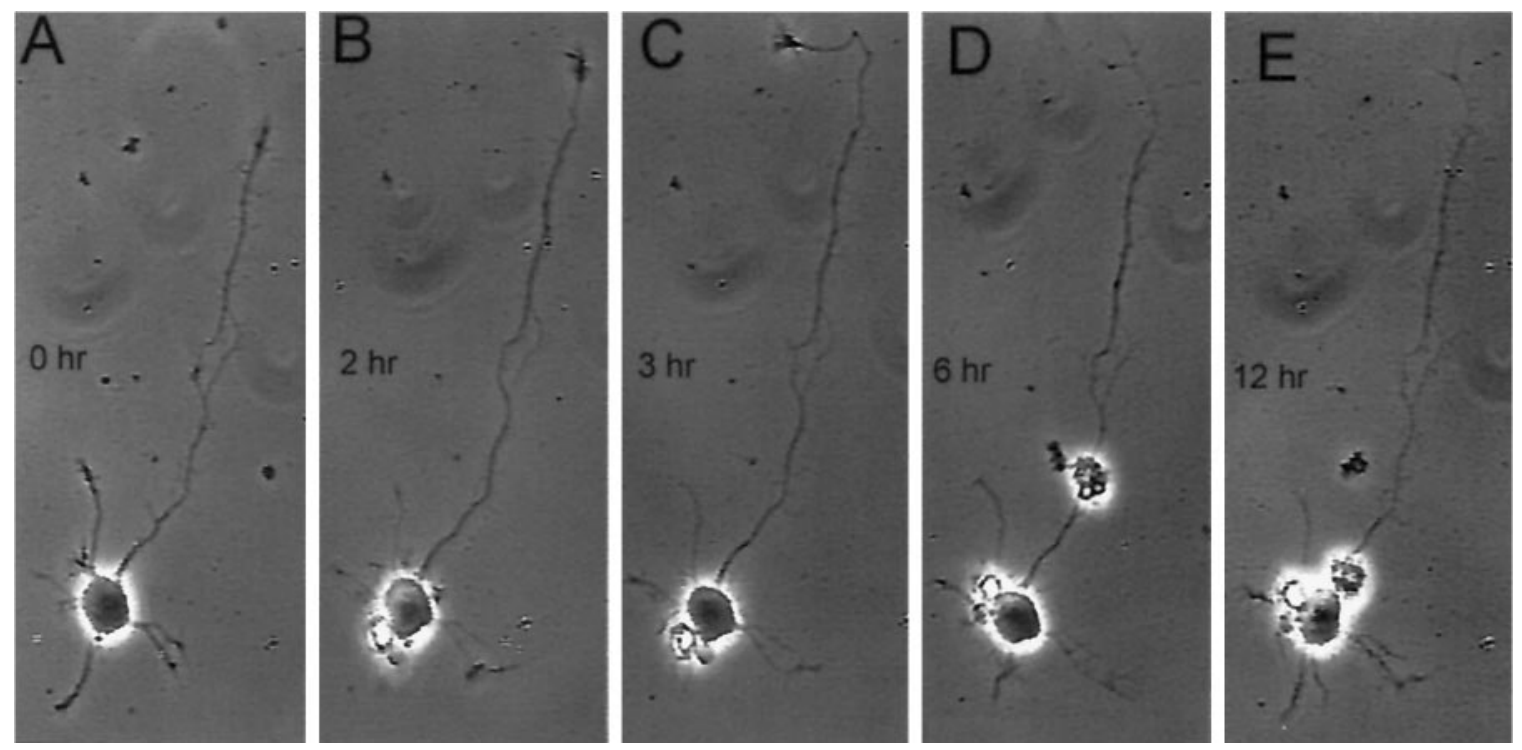

Figure 8. The effects of cycloheximide on neurite elongation. The set of phase contrast micrographs illustrates a cell just before treatment with $71 \mu \mathrm{M}$ cycloheximide $(A)$ and $2 \mathrm{hr}(B), 3 \mathrm{hr}(C), 6 \mathrm{hr}(D)$, and $12 \mathrm{hr}(E)$ after treatment. Axonal growth continued normally for $3 \mathrm{hr}$ after the addition of cycloheximide. By $6 \mathrm{hr}$, the axon had stopped growing and had retracted slightly, and its growth cone had disappeared. Over the next 6 hr, the axon became thinner and retracted still more. The minor processes also became thinner over time, but they did not retract. Scale bar, $20 \mu \mathrm{m}$.

against this hypothesis. If both BFA and $\mathrm{CHX}$ act by depleting the availability of particular membrane proteins, then the difference in the time course of their effects should reflect the point at which these drugs block protein traffic along the exocytic pathway. The transit time from the ER to the cell surface for typical membrane proteins is in the range of 1-2 hr (Lundstrom et al., 1993; Thorens et al., 1993; Akasaki et al., 1995; Pimental et al., 1996). Only 1-2 min would be required for vesicles to travel to the growth cone by rapid transport. Yet, growth of CHX-treated axons was not affected until $3-4.5 \mathrm{hr}$ after drug addition. Some multisubunit receptors do reside intracellularly for longer than 3 hr (Vitetta and Uhr, 1975; Devreotes et al., 1977). However, in other types of neurons, inhibition of axonal growth by protein synthesis inhibitors requires an even longer time (Daniels, 1973; Estridge and Bunge, 1978; Lein and Higgins, 1991). Furthermore, differences in the morphology of BFA- and CHX-treated neurons suggest their mechanisms of action may be different. The inhibition of axonal growth by $\mathrm{CHX}$ treatment coincided with loss of the growth cone and a thinning of the axon, whereas in BFAtreated axons the growth cone remained motile for hours after net elongation had stopped.

An alternative explanation of the effects of BFA treatment on axonal elongation is that the lipid components of the Golgiderived vesicles are required for axonal growth. Logically, availability of bulk lipids should be required for growth, because the concomitant increases in surface area and volume of a growing axon would require the net addition of membranous material. Dai and Sheetz (1995) have proposed a model in which membrane tension could act to regulate neurite growth. In chick DRG neurons, they observed that the axonal membrane flowed toward the cell body, consistent with a relatively low membrane tension at the growth cone and a relatively high membrane tension at the cell body. In cases in which the membrane tension at the growth cone increases, such as with BFA treatment (Dai and Sheetz, 1995), elongation of a neurite necessarily requires a stronger motile force. Increased membrane tension, caused by BFA blocking the insertion of new membrane, may be the mechanism by which axonal elongation ceases; if the tension at the growth cone reached a high enough level, then filopodial extension would tend to be inhibited, and retraction could be favored.

Perturbations in the levels of a single lipid species in the plasma membrane can also have significant effects on neurite outgrowth. For example, inhibitors of sphingolipid synthesis were shown to inhibit axonal or dendritic growth in a number of different neurons (Harel and Futerman, 1993; Furuya et al., 1995; Boldin and Futerman, 1997; Dechaves et al., 1997). However, many of these effects require many hours or days in contrast to the rapid effects of BFA.

\section{The development and maintenance of polarity}

In hippocampal cultures, the transition a neuron undergoes from an apparently unpolarized cell with several identical neurites to a cell with a single axon that has acquired its defining morphological and molecular properties occurs quite abruptly, in as little as $1 \mathrm{hr}$ (Dotti et al., 1988; Goslin and Banker, 1989; Deitch and Banker, 1993). What induces this critical developmental transition? One possible explanation is that this phenotypic change is initiated by the induction of new gene expression or by the increased expression of certain key protein(s). The slow time course with which inhibitors of RNA or protein synthesis block the development of polarity argues against these possibilities. The percentage of cells with axons increased normally in the presence of CHX for at least $3 \mathrm{hr}$ and in the presence of ACT D for at least $6 \mathrm{hr}$. This suggests that the full complement of proteins and mRNA required for the development of polarity can be present for several hours before polarity is actually established.

When axons of 1-d-old neurons are transected near the cell body, the polarity of the cell is often altered (Goslin and Banker, 1990). A different neurite becomes the axon. When lesions are made at greater distances, the lesioned axon retains its identity. One hypothesis put forth to explain these effects is that the influx of $\mathrm{Ca}^{2+}$ at the lesion site and its spread to the cell body determined which process eventually became the axon (Mattson et al., 1990). The present results show that polarity can be altered when 
A
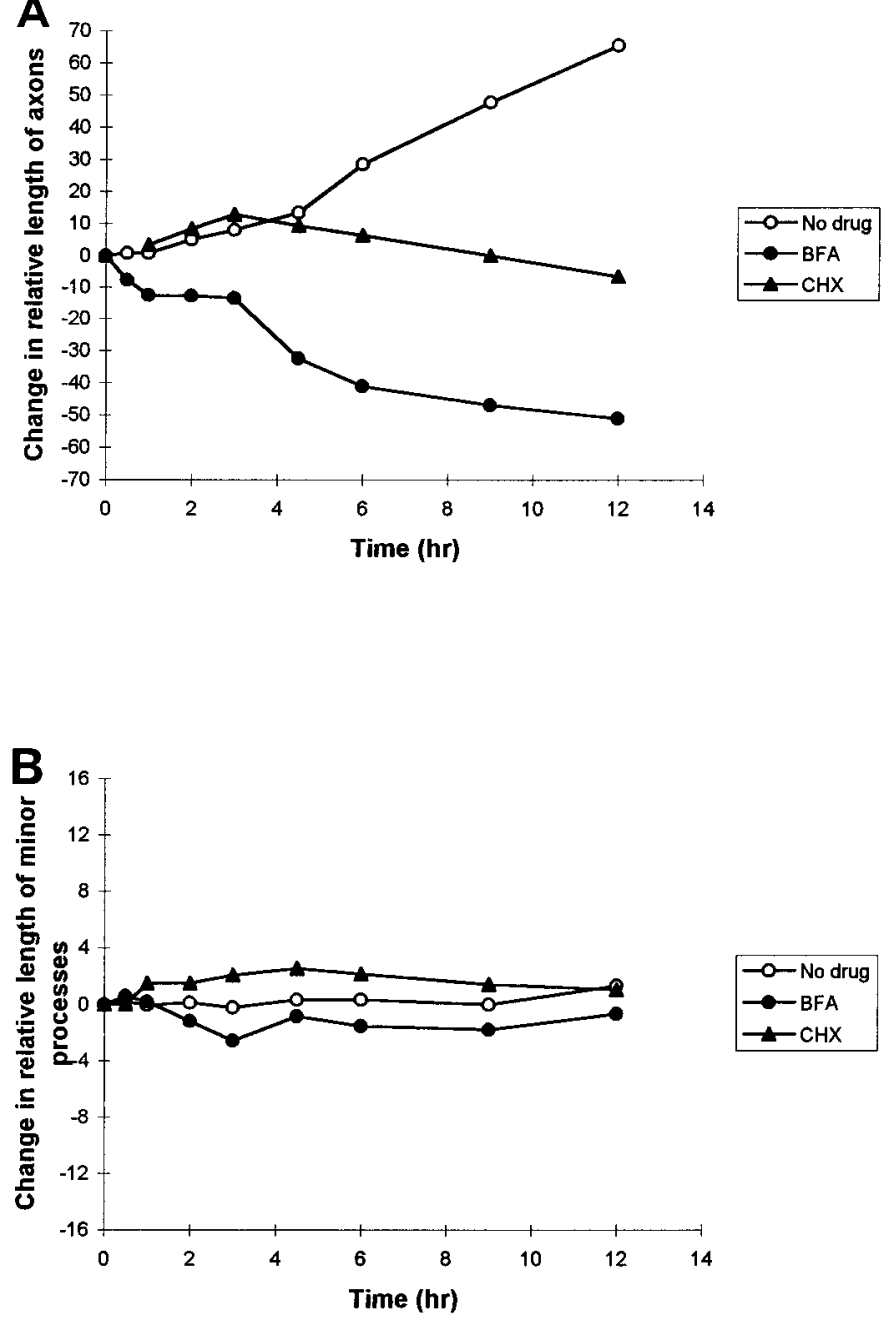

Figure 9. A comparison of the effects of brefeldin A and cycloheximide on the rate of neurite elongation. $A, B$, An illustration of the average net change in the length of the axon $(A)$ and of the minor processes $(B)$, measured relative to the length of these processes at the time drug treatment began $(\sim 24 \mathrm{hr}$ after plating). Cultures treated with BFA (3.57 $\mu \mathrm{M}$; filled circles) or with cycloheximide (71 $\mu \mathrm{M}$; filled triangles) were compared with control cultures treated with EtOH or $\mathrm{H}_{2} \mathrm{O}$, respectively (open circles). Axonal growth was significantly inhibited within $1 \mathrm{hr}$ after treatment with BFA $(p<0.001$, BFA vs controls). At later times BFAtreated axons exhibited a net retraction, which reached an average of 51.1 $\mu \mathrm{m}$ by $12 \mathrm{hr}$. The rate of axonal growth in cycloheximide-treated cells was not significantly different from that of control cells until after $6 \mathrm{hr}$ of treatment. At later times cycloheximide-treated axons exhibited a net retraction, which reached an average of $6.6 \mu \mathrm{m}$ by $12 \mathrm{hr}$. At this stage of development, minor processes exhibit little or no net growth. Neither BFA nor cycloheximide caused a systematic change in the length of minor processes. These data are based on measurements of 24 randomly chosen stage 3 cells from two independent experiments.

BFA treatment causes axons to retract. BFA treatment is unlikely to induce the influx of $\mathrm{Ca}^{2+}$.

\section{Conclusion}

One key to understanding axonal growth and the development of polarity is the regulation of the trafficking of required materials. Much of the research concerning axonal growth has focused on the growth cone because it seems to be the primary site for the assembly and disassembly of the cytoskeleton involved in process outgrowth. The regulation of growth must also depend on the
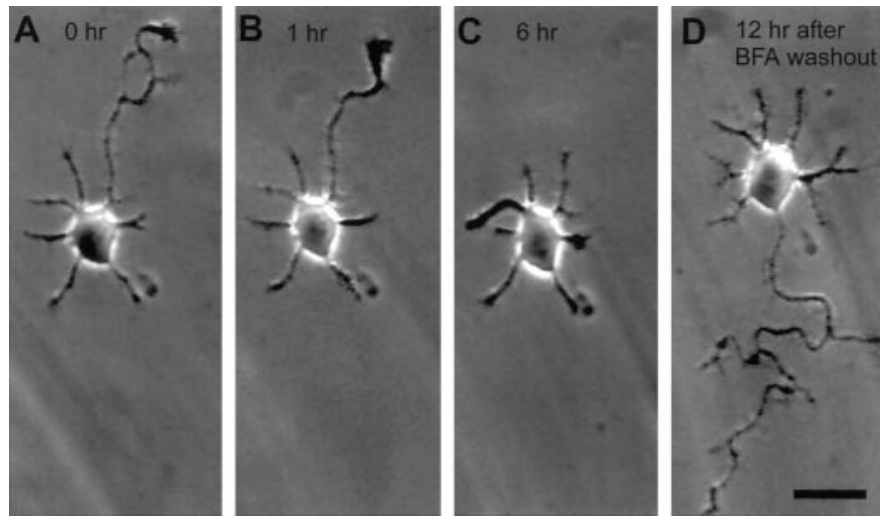

Figure 10. Alteration of polarity induced by brefeldin A. This set of phase contrast micrographs illustrates a cell just before BFA treatment $(A), 1 \mathrm{hr}(B)$ and $6 \mathrm{hr}(C)$ after the addition of BFA, and then $12 \mathrm{hr}$ after BFA was removed and the cell was returned to control medium $(D)$. Within $1 \mathrm{hr}$ of BFA treatment, the axon had begun to retract, and by $6 \mathrm{hr}$, it had retracted back to the length of the minor processes of the cell. After removal of BFA, the initial axon did not regrow. Instead one of the minor processes became the new axon. Scale bar, $20 \mu \mathrm{m}$.

supply of membranous elements. The data presented here show that changes in the availability of Golgi-derived materials can also affect the outgrowth of axons. Further work examining vesicular trafficking during periods of selective growth of neurites should provide insight into how cells coordinate the supply of membrane material with the demands of growth.

\section{REFERENCES}

Akasaki K, Fukuzawa M, Kinoshita H, Furuno K, Tsuji H (1993) Cycling of two endogenous lysosomal membrane proteins, lamp-2 and acid phosphatase, between the cell surface and lysosomes in cultured rat hepatocytes. J Biochem (Tokyo) 114:598-604.

Andreose JS, Fumagalli G, Sigworth FJ, Caplan MJ (1996) Real-time detection of the surface delivery of newly synthesized membrane proteins. Proc Natl Acad Sci USA 93:7661-7666.

Barroso M, Sztul ES (1994) Basolateral to apical transcytosis in polarized cells is indirect and involves BFA and trimeric $\mathrm{G}$ protein sensitive passage through the apical endosome. J Cell Biol 124:83-100.

Boldin S, Futerman AH (1997) Glucosylceramide synthesis is required for basic fibroblast growth factor and laminin to stimulate axonal growth. J Neurochem 68:882-885.

Bottenstein JE, Sato GH (1979) Growth of a rat neuroblastoma cell line in serum-free supplemented medium. Proc Natl Acad Sci USA 76: 514-517.

Cid-Arregui A, Parton RG, Simons K, Dotti CG (1995) Nocodazoledependent transport, and brefeldin A-sensitive processing and sorting, of newly synthesized membrane proteins in cultured neurons. J Neurosci 15:4259-4269.

Craig AM, Wyborski RJ, Banker G (1995) Preferential addition of newly synthesized membrane protein at axonal growth cones. Nature 375:592-594.

Dai J, Sheetz MP (1995) Axon membrane flows from the growth cone to the cell body. Cell 83:693-701.

Damke H, Klumperman J, von Figura K, Braulke T (1991) Effects of brefeldin A on the endocytic route. Redistribution of mannose 6phosphate/insulin-like growth factor II receptors to the cell surface. J Biol Chem 266:24829-24833.

Daniels MP (1973) Fine structural changes in neurons and nerve fibers associated with colchicine inhibition of nerve fiber formation in vitro. J Cell Biol 58:463-470.

Dascher C, Balch WE (1994) Dominant inhibitory mutants of ARF1 block endoplasmic reticulum to Golgi transport and trigger disassembly of the Golgi apparatus. J Biol Chem 269:1437-1448.

de Hoop M, von Poser C, Lange C, Ikonen E, Hunziker W, Dotti CG (1995) Intracellular routing of wild-type and mutated polymeric im- 
munoglobulin receptor in hippocampal neurons in culture. J Cell Biol 130:1447-1459.

Dechaves EIP, Bussiere M, Vance DE, Campenot RB, Vance JE (1997) Elevation of ceramide within distal neurites inhibits neurite growth in cultured rat sympathetic neurons. J Biol Chem 272:3028-3035.

Deitch JS, Banker GA (1993) An electron microscopic analysis of hippocampal neurons developing in culture: early stages in the emergence of polarity. J Neurosci 13:4301-4315.

Devreotes PN, Gardner JM, Fambrough DM (1977) Kinetics of biosynthesis of acetylcholine receptor and subsequent incorporation into plasma membrane of cultured chick skeletal muscle. Cell 10:365-373.

Donaldson JG, Finazzi D, Klausner RD (1992) Brefeldin A inhibits Golgi membrane-catalysed exchange of guanine nucleotide onto ARF protein. Nature 360:350-352.

Dotti CG, Banker G (1991) Intracellular organization of hippocampal neurons during the development of neuronal polarity. J Cell Sci Suppl 15:75-84.

Dotti CG, Banker GA (1987) Experimentally induced alteration in the polarity of developing neurons. Nature 330:254-256.

Dotti CG, Sullivan CA, Banker GA (1988) The establishment of polarity by hippocampal neurons in culture. J Neurosci 8:1454-1468.

Elazar Z, Orci L, Ostermann J, Amherdt M, Tanigawa G, Rothman JE (1994) ADP-ribosylation factor and coatomer couple fusion to vesicle budding. J Cell Biol 124:415-424.

Estridge M, Bunge R (1978) Compositional analysis of growing axons from rat sympathetic neurons. J Cell Biol 79:138-155.

Furuya S, Ono K, Hirabayashi Y (1995) Sphingolipid biosynthesis is necessary for dendrite growth and survival of cerebellar Purkinje cells in culture. J Neurochem 65:1551-1561.

Goldberg DJ, Schacher S (1987) Differential growth of the branches of a regenerating bifurcate axon is associated with differential axonal transport of organelles. Dev Biol 124:35-40.

Goslin K, Banker G (1989) Experimental observations on the development of polarity by hippocampal neurons in culture. $\mathrm{J}$ Cell Biol 108:1507-1516.

Goslin K, Banker G (1990) Rapid changes in the distribution of GAP-43 correlate with the expression of neuronal polarity during normal development and under experimental conditions. J Cell Biol 110: 1319-1331.

Goslin K, Banker G (1992) Rat hippocampal neurons in low density culture. In: Culturing nerve cells (Banker G, Goslin K, eds), pp 252281. Cambridge, MA: MIT.

Harel R, Futerman AH (1993) Inhibition of sphingolipid synthesis affects axonal outgrowth in cultured hippocampal neurons. J Biol Chem 268:14476-14481.

Helms JB, Rothman JE (1992) Inhibition by brefeldin A of a Golgi membrane enzyme that catalyses exchange of guanine nucleotide bound to ARF. Nature 360:352-354.

Herz J, Gerard RD (1993) Adenovirus-mediated transfer of low density lipoprotein receptor gene acutely accelerates cholesterol clearance in normal mice. Proc Natl Acad Sci USA 90:2812-2816.

Hunziker W, Harter C, Matter K, Mellman I (1991) Basolateral sorting in MDCK cells requires a distinct cytoplasmic domain determinant. Cell 66:907-920.

Kleiman R, Banker G, Steward O (1993) Inhibition of protein synthesis alters the subcellular distribution of mRNA in neurons but does not prevent dendritic transport of RNA. Proc Natl Acad Sci USA 90:11192-11196.

Ktistakis NT, Brown HA, Sternweis PC, Roth MG (1995) Phospholipase D is present on Golgi-enriched membranes and its activation by ADP ribosylation factor is sensitive to brefeldin A. Proc Natl Acad Sci USA 92:4952-4956.

Ktistakis NT, Brown HA, Waters MG, Sternweis PC, Roth MG (1996)
Evidence that phospholipase D mediates ADP ribosylation factordependent formation of Golgi coated vesicles. J Cell Biol 134:295-306.

Lein PJ, Higgins D (1991) Protein synthesis is required for the initiation of dendritic growth in embryonic rat sympathetic neurons in vitro. Dev Brain Res 60:187-196.

Lippincott-Schwartz J, Yuan L, Tipper C, Amherdt M, Orci L, Klausner RD (1991) Brefeldin A's effects on endosomes, lysosomes, and the TGN suggest a general mechanism for regulating organelle structure and membrane traffic. Cell 67:601-616.

Lipsky NG, Pagano RE (1985) A vital stain for the Golgi apparatus. Science 228:745-747.

Lundstrom M, Orlando RA, Saedi MS, Woodward L, Kurihara H, Farquhar MG (1993) Immunocytochemical and biochemical characterization of the Heymann nephritis antigenic complex in rat L2 yolk sac cells. Am J Pathol 143:1423-1435.

Martenson C, Stone K, Reedy M, Sheetz M (1993) Fast axonal transport is required for growth cone advance. Nature 366:66-69.

Matter K, Whitney JA, Yamamoto EM, Mellman I (1993) Common signals control low density lipoprotein receptor sorting in endosomes and the Golgi complex of MDCK cells. Cell 74:1053-1064.

Mattson MP, Murain M, Guthrie PB (1990) Localized calcium influx orients axon formation in embryonic hippocampal pyramidal neurons. Dev Brain Res 52:201-209.

Mundigl O, Matteoli M, Daniell L, Thomas-Reetz A, Metcalf A, Jahn R, De Camilli P (1993) Synaptic vesicle proteins and early endosomes in cultured hippocampal neurons: differential effects of brefeldin A in axon and dendrites. J Cell Biol 122:1207-1221.

O'Rourke NA, Fraser SE (1990) Dynamic changes in optic fiber terminal arbors lead to retinotopic map formation: an in vivo confocal microscopic study. Neuron 5:159-171.

Pagano RE, Martin OC, Kang HC, Haugland RP (1991) A novel fluorescent ceramide analogue for studying membrane traffic in animal cells: accumulation at the Golgi apparatus results in altered spectral properties of the sphingolipid precursor. J Cell Biol 113:1267-1279.

Pimental RA, Julian J, Gendler SJ, Carson DD (1996) Synthesis and intracellular trafficking of Muc-1 and mucins by polarized mouse uterine epithelial cells. J Biol Chem 271:28128-28137.

Prydz K, Hansen SH, Sandvig K, van Deurs B (1992) Effects of brefeldin A on endocytosis, transcytosis and transport to the Golgi complex in polarized MDCK cells. J Cell Biol 119:259-272.

Schonhorn JE, Wessling-Resnick M (1994) Brefeldin A down-regulates the transferrin receptor in K562 cells. Mol Cell Biochem 135:159-169.

Stoorvogel W, Oorschot V, Geuze HJ (1996) A novel class of clathrincoated vesicles budding from endosomes. J Cell Biol 132:21-33.

Thorens B, Gerard N, Deriaz N (1993) GLUT2 surface expression and intracellular transport via the constitutive pathway in pancreatic beta cells and insulinoma: evidence for a block in trans-Golgi network exit by brefeldin A. J Cell Biol 123:1687-1694.

Vitetta ES, Uhr JW (1975) Immunoglobulins and alloantigens on the surface of lymphoid cells. Biochim Biophys Acta 415:253-271.

Wan J, Taub ME, Shah D, Shen WC (1992) Brefeldin A enhances receptor-mediated transcytosis of transferrin in filter-grown MadinDarby canine kidney cells. J Biol Chem 267:13446-13450.

Wieland FT, Gleason ML, Serafini TA, Rothman JE (1987) The rate of bulk flow from the endoplasmic reticulum to the cell surface. Cell 50:289-300.

Young Jr WW, Lutz MS, Blackburn WA (1992) Endogenous glycosphingolipids move to the cell surface at a rate consistent with bulk flow estimates. J Biol Chem 267:12011-12015.

Zhang CJ, Rosenwald AG, Willingham MC, Skuntz S, Clark J, Kahn RA (1994) Expression of a dominant allele of human ARF1 inhibits membrane traffic in vivo. J Cell Biol 124:289-300. 